\title{
A feedback culture for a performance culture
}

\author{
Madalina Mirela RADULESCU \\ The Bucharest University of Economic Studies, Bucharest, Romania \\ madalina.radulescu@fun-training.ro
}

\begin{abstract}
In today's business world people have to face complexity, unpredictability and continuous change. In a worldlike this, time is the most requested resource and, apparently, everybody blames time for non-accomplishing business objective and good relationships between colleagues. Thus, feedback becomes a requested instrument that might help people within organizations to achieve the desired performance. When speaking of feedback, we will refer to its definition and perception about it within organization, but also outside organization between, different actors on the commercial processes, therefore several levels will be approached. On vertical, the transfer top-bottom and bottom-top (different hierarchical levels) and on horizontal, the transfer between peers but also between clients and providers and vice versa.More and more companies are looking for development programs that develop team cohesion. In order to createa performance culture and feedback to be practice as a development tool, we will identify a series of competencies to be developed, so that in the end to have an answer to the question: Can a feedback culture build a performance culture? The proposed article'sobjective is to bring your attention to what leaders and members of an organization can do in order to ensure a proper culture of performance based on feedback. The article is based on a critical analysis of literature and a qualitative analysis of the opinions investigated by the author into practice.
\end{abstract}

Keywords:leadership, performance, feedback, sustainability.

\section{Introduction}

Every crisis appears as an effect of actions previously made. We might say that a crisis is an output based on different inputs on a given context. Humanity faces today a crisis of leadership at personal level but also on hierarchical levels.

Complexity, unpredictability and continuous change are the facets of the new world, a world that started to be studied and anticipated in 1933 by Grigore Antipa, introducing the bio economy concept, and Nicolae Georgescu-Roegen in the 70s whose efforts led to the issue of ecological economics which was later developed by Daly, Constanza, Donella Meadows, Brown and others. This ended in the eco-economy concept, based on a transdisciplinary and multi-disciplinary approach that opens up new opportunities for the study and the reuse of economic processes in correlation with the environment and the social that leads to the issue of new activity fields and jobs that rely on continuous learning, creativity and innovation. In this way, the eco-economy is to be considered as started from the need of changing the vision and understanding on success and performance by enlarging the view to maintain and conserve the environment and social wealth. In this context, long term thinking, and comprehension of natural processes can lead to a better understanding of the connections between the economic, social and natural systems. Comparing the hypothesis to the business environment every business should be assessed in a social frame, through the operation of a community that takes resources and that, on balance principle should be redistributed ensuring growth and development for all stakeholders. 
There is a paradox, although the context has been changed and sustainability is a concept claimed by almost all companies emphasizing on the need of long term view of businesses through the lentils of economic, social and environment pillars, the pressure on short financial results is still overspread. As a consequence, the time pressure affects behaviors of both leaders and employees. Businesses are operating in a post-industrial, service-based economy, but companies are managed by models develop in, by and for industrial corporations (Davis, 1984:2). Managers over-relied on complex structures, elaborate systems and formalistic planning mechanisms, with disastrous results. (Brown, 1998). These warning signals raised more than 30 years ago are still in. Adding the digital revolution that imposed new way of communicating and managing information, and an overexposure on social media, the pressure on dealing the day to day operations and to relate with people around become an art. Focusing on sustainability requires putting business strategies to a new test. (Hart, 2007) Adopting strategies to build trust and encourage a transparent communication seems to be part of the social footprint that companies can create.

This paper is about what management and leadership can do in order to create a culture of performance through feedback, starting with the meaning of feedback and furthermore presenting the way to practice it. In view of this paper we will refer to leadership at both levels, personal and team.

\section{Methodology}

The researchmethodologyconsists on a theoreticalapproach by criticalanalysis of concernedliteraturebackedup on the practicalsidewithfeedback obtained by participants to development programsin organizations on team cohesion and on the subject of feedback in itself.

To face new frame, new types of working places and the development of new working fields that rely on learning and creativity are created with a focus on a culture of sharing. It is considered that the eco-economy is based on reconsidering the historical heritage of the processes and products created without evaluating the impact on the environment. By improving the heritage, people will have to reinvent themselves and it is to be seen as the biggest challenge of the century. People will have to assume own development as part of the personal leadership. This process can take place through the integration of eco-economy principles in everyday activities and life. The statistics show that it has been working on the implementation of this action since four decades of which fifteen years were dedicated only to defining the proper type of development called sustainable development. Since then, the practice of leadership evolved, new theories appeared but on the practical side things seem to come back to the old origin: keeping them as simple as we can. One word is still complex and well spread: performance. No matter what the industry is, field of activity, company, school, team or individual, everybody on managerial position ask for performance.

Introducing the concept of performance management was a good value for companies. Unfortunately, what we've seen on practice is that on the implementation phase, the concept started to be assimilated with performance appraisal and the idea of the continuum management based on permanent feedback was actually replaced with one single annual feedback meeting with the occasion of the performance appraisal. If 
performance is considered the result of potential diminished by interferences, feedback can be the tool to eliminate/diminuate the interferences.

The meaning of feedback, according to Oxford living dictionary is: "Information about reactions to a product, a person's performance of a task, etc. which is used as a basis for improvement." Feedback is a term that comes from the field of Physics. It appeared as a distinct word in 1920 in the electronic sense as" the return of a fraction of an output signal to the input of an earlier stage". By 1955, the definition became" information about the results of a process". Nature is full of feedback loops, it is about a cause - effect process that was furthermore took over on the management field, so that the definition itself goes us with the mind that feedback is a tool for improving performance. Feedback depends on the quality of the relationship between two or more people, in which both the giver and the receptor may add value.

It is recognized that feedback is part of the performance management process. Years, feedback was considered in the scope of the performance appraisal meeting. Managers were trained on how to give it, still author's observations made on companies reveal that although trained, people are not conscious about the importance and meaning of feedback, the "why" of feedback as Simon Sinek would say in his theory about The Golden Circle. On a research made on the last year, the following negative statements have been collected from leaders on giving feedback: There is no time to give feedback, I have such a lot of things to do; Why to bother to give feedback if everything goes well; If I give people positive feedback, they will consider me too soft;, People do not accept my feedback, they do not listen to m; If I tell people negative things, they will not like me anymore and they will be disengaged.

On the same time, employees, receiving feedback made the following statements: $M y$ boss is not natural when giving feedback; My boss is looking only for my mistakes; How can I give feedback in my turn to my boss, he will not allow this, it is better to renounce on giving it. (source: own observations of the author).

The above-mentionedstatements are raised based on the perceptions on real life stories, previous exposure, cultural biases and early education. It looks to the author that people eventually did not understood the meaning of feedback and the positive side of it. These repeatedly excuses received on the training rooms but also during interviews made with leaders and employees, made us search for more advanced studies on the impact of different kinds of feedback on employees at global level.A 2009 Gallup Inc. study of over 1,000 U.S. askedeachworker to rate their manager on whether they focused on their strengths or positivecharacteristics or whether they focused on their weaknesses or negative characteristics. Respondentsnotchoosingeitherdescriptionwereclassified in the study as beingignored by their manager.The conclusion are shownbellow:

1. One in 10 supervisors focus on employeeweaknesses.

2. Employeesreceivingpredominantly negative feedback from their manager are over 20 times more likely to be engaged than thosereceivinglittle or no feedback.

3. Employeesignored by their manager are twice as likely to be activelydisengagedcomparedwithworkerswhose manager focuses on their weaknesses.

4. Managersfocusing on employeestrengths are 30 times more likely to manageactivelyengagedworkerscomparedwithmanagersdenying feedback.

5. Managersfocusing on employeestrengths are onethird more likely to manageactivelyengagedemployeescomparedwithmanagersfocusing on weaknesses. 
6. Managersgivinglittle or nofeedback to employeesresult in 4 out of 10 workersbeingactivelydisengaged.

7. $43 \%$ of highlyengagedemployeesreceive feedback at leastonce a week.

Recently, large companies like Accenture, GE have announced that they renounce to the annual performance appraisal review replacing it with an ongoing management based on permanent feedback. This new approach comes with the argument that people need guidance in order to improve their performance. Early intervention allows performance to raise, or to correct if it is about underperformance. Besides the numerous advantages, this could also cause some disadvantages, too, as the main responsibility will rather be passed to the direct supervisor's. In this respect, unless the latter is characterized by a high level of emotional intelligence that makes him capable to identify the moment when it is necessary to abandon old habits or courses of action and adopt new ones, the new feedback approach does not lead to significant improvements (Ghinea, 2016).

Based on author's research done on groups of managers, one of the traits that appear in giving-receiving feedback process is the shortage in timethat managers claim due to other business priorities. It is to be said that, under the pressure of deadlines, often managers consider feedback as non-important. People are stressed under the realization of performance indicators, so that little time rests to be allocated on giving feedback. This is generated by a short-term focus on objectives rather than a long term. On the profound levels it is, also, about the fear of others' reaction caused by the feedback. Eventually, people are unsecure and live with the sensation that the others will not like them anymore if they give negative feedback and they are fighting for being accepted.Human mind stores information contextually, including cues like environment and correlation. Because the brain is a pattern matching machine, it's constantly trying to figure out what's associated with what. As a result, the mind effortlessly forms associations - even between things that aren't logically connected. (Kaufman, 2010). On other words, once someone has the experience of a bad feedback associated with a punishment, the openness to give and receive feedback is more likely associated with a bad experience than to a performance generator experience.

"Organizational culture impacts performance. However, this is not a simple direct relationship". Researches show that Constructive styles, identified as per Organizational Culture Instruments developed by Human Synergistic,are: Humanistic Encouraging, Affiliative, Achievement and Self-actualizing) and they positively correlate with desirable organizational outcomes, such as high staff and customer satisfaction, sales growth, profitability and shareholdervalue (Cooke and Szumal, 2000).

In an organization in which people are willing to share experiences and are not afraid of being judged, the communication is open and transparent, and people take time to understand each other's frame of reference, own values comparing with organization's official values. Acting like that is a characteristic of a long-term approach rather than a short-term approach and increases the trust between the members. It is also a sign of social responsibility, of caring about the self-wealth simultaneously with the others' wealth.If we enlarge the context to the external environment of a company, exchanging feedback with clients and suppliers or other partners is beneficial for the whole system performance. As a provider it is important to know the feedback of the client in order to improve services, offers, products. Unless a trusted relationship is developed, feedback is almost sure will not come. 


\section{Results and discussions}

Giving feedback is a skill that cannot be learnt from a book. (Cameron, 2001). As shown on the previous part of this article, practicing feedback consciously is not really easy because of the people perceptions about it.

First of all, acquiring new skills put everyone in a context of change management, therefore understanding "the why" of changing in behavior is a key point of any learning organization. This type of organizations has the capacity to adjust well to any change in their environment and create the necessary frame for the people inside to think, to observe, to understand, to unlearn and then relearn, to challenge the status quo and innovate. (McKenna, Beech, 2002)

The so called two-way feedback is not about the watcher acting alone. It is that kind of a culture in which all employees can act as support for the others by observing performance against procedures, code of conduct, key indicators, attitude, morale of the team. They are encouraged to ask or check if something goes good or wrong keeping in mind that there are several principles to be followed: be linked to specific observed behavior; be descriptive non-judge mental; be limited and focused, not overwhelming; be two-way, based on questions and discussions; be focused on performance, not personality; be conclusive with prescriptive outcomes; be presented in a professional way (Carter, E. M. A. ; McMahon, F.A. 2005). Participants are instructed to practice a state of presence that bring trust and enthusiasm to the group. (Cuddy, 2016)

Secondly, opening the window for "feedback" may end, at least at the beginning of the process, with some disruptions at the level of the relationships, thus first thing to change or adjust is the attitude towards feedback as this being a form of carrying, empowerment and engagement (as shown previously on statistics), because the giver shows that payed attention to what happened in the past and take measures in present in order to improve something in the future. People are also instructed to be aware of main sources of errors in perception and how to avoid/remediate them.

If people are to improve their understanding of others, they must have a welldeveloped knowledge of theirselves - their strenghts, their preferences, their flaws and biases. The development of self knowledge might be an unconfortable process. In organizational settings, people are often constrained in the expression of feelings about other people due to social and cultural norms and to communication barriers imposed by power differentials (Buchanan, Huczynski, 2004)

In the World Economic Forum - Future of jobs report, 2016, it is stated that by 2020, creativity, critical thinking, coordinating with others and judgement \& decision making will be on Top 10 of the required skills from people.

When trying to improve something, it is not clear what approach may bring the desired outcome. The constant experimentation is actually the only way someone may identify what actually will produce the desired result. A good approach would be to practicefeedback in a safe environment, meaning a trustworthy support group. It can be a professional team, a peer coaching team, or any other structure that offers to its member a wide level of trust. At the beginning, the supervision of an expert is mandatory, a facilitator whose objective is to firstly bring trust within the group and then motivate the group to practice in order to develop strong feedback skills, learn how to let people know when they accomplished an objective or when they are on a good path but also learn how to let people 
know when they need to correct their approach. Support is absolutely essential in improving group performance. It is very easy to give feedback in a holier than thou fashion, which carries the message that the observer is infinitely superior to the observed, and in possession of secret knowledge of all the observer's faults. Since our social interactions are an area in which most people feel vulnerable, such feedback can be highly destructive. The group needs an agreement beforehand on how it wants feedback given, and a commitment to supporting its members in their efforts to improve in the light of feedback. (Cameron, 2001) Giving feedback on the right, proper way is a sign of responsibility of the manager that in turns raises the responsibility of the employee and ultimately increases the level of trust between the two but also amongst the members of the team in case performance level is adjusted on a positive scale.

Independent on the way of practicing feedback, in a group or at personal level taking the opportunities that day-to-day life is offering to someone, the 4P Model: Plan, Practice, Patient, Perseverance (Holliday, 2010) can be of help in establishing a strategy on what to do as a feedback giver but also receiver. The way people learn is very different, but one condition is important, to develop the "observatory" capabilities. Observing is a first step in developing creativity and critical thinking. As a receiver you might observe your reactions, what you like or dislike in the way it was communicated to you. As a giver you may encounter reactions that allows you to adjust the way you will act next time in a similar occasion. Self-observations or auto evaluation helps to understand you better and how to relate to the others.

Working in peer groups in different roles may speed the way someone develops the observations capabilities. Usually people learn more from what doesn't go well. So, paying attention to flows, processes, reactions can give useful information for what could go better. What happens usually in such groups is that people come with different issues and end to the conclusion that they are so similar. Listening to the other members' feedback, experience, way of acting/approaching things, enlarges the context for personal understanding. The more people practice within the support group, the biggest are the chances to apply the new methods on their real life because they overpass the fear being prepared for different reactions. Their changing behavior will challenge the context (the partners, employees, managers, peers) and will force their system to adjust so that a systemic change will take place in time.

Practiced also showed that in the organization in which people were put in situation to listen to each other, to understand not only their job role but also to discover their core values, performance of the team increased, the results being observed by the clients. Observing the dynamic of such a group it was interesting to see how two people that used to be on the same team but working on different activities, discovered their common values just observing, listening and practicing feedback after the second meeting.

Practicing in groups also help in developing the skills of coordinating with others, because everyone has roles and responsibilities and if someone is not respecting them, the group performance lowers.

\section{Conclusions}

Feedback is the instrument used not only at micro level but also at macro level. It is a sign of responsibility towards the actors with whom we interact in running the day to day business. Companies, through their leaders, have the responsibility to provide the accurate 
frame of reference for the employees to perform their jobs in the best conditions. But considering the principle of the eco-economy companies, act in an environment where development is co-created by all the components, therefore every action or non-action impact this environment's performance. Not giving feedback to inputs from outside, discourages the other actors and in the end, may affect a whole market.

It is the moment to stop using "short term debt to finance long term results". It is time to allocate proper time for personal and professional developmentfor sharing and acting courageously with responsibility and acting from trust not from fear. The good news is that behaviors can be changed overtime, recognizing them and acting consciously to correct where appropriate.

A feedback culture can be built by understanding the meaning of feedback, changing the attitude towards the feedback as a carrying one, practicing feedback in a safe, trusted group, learning to observe and listen carefully to the others but also trying to understand emotions behind reactions. Feedback should focus on good aspects even more than bad ones. This will reinforce strengths as well as making the recipient feel strong enough in facing his limits without becoming defensive. As shown, feedback increases the level of engagement thus the level of performance within and outside companies. Some limits still exist: the reluctance to honestly approaching and speaking about feedback, fear in expressing emotions in an assertive way, people's perception that feedback is a second priority. Potentially other limits will be discovered by continuing the field observations by the author.

If people understand their role on the society, company, their life, may have a chance to act responsible and create a sustainable performance ensuring the "social health and wealth".

\section{References}

Brown, A. (1998), Organizational Culture Second Edition, Financial Times Prentice Hall, pp. 3.

Buchanan, D., Huczynski, A., 2004, Organizational Behaviour, an introductory text, Financial Times Prentice Hall, pp. 234.

Cameron, S. (2001), The MBA Handbook, Financial Times Prentice Hall, pp. 149-154.

Carter, E. M. A., McMahon, F. A. (2005), Improving Employee Performance through workplace coaching, Kogan Page, pp. 53-57.

Cooke, R. A.; Szumal, J. L.(2000), Using the organizational culture inventory to understand the operating cultures of organizations, Handbook of organizational culture and climate. Thousand Oaks, CA, Sage.

Costanza, R. et all (1997), An introduction to ecological economics, St Lucie Press, Florida.

Cuddy, A. (2016), Prezenta, EdituraPublica, pp. 38.

Davis, S. M. (1984), Managing Corporate Culture, Cambridge Mass: Ballinger.

Garvin, D. (1993), Building a learning organization, Harvard Business Review, July-August, pp. 78-91.

Ghinea, V.M. (2016), Organizational Culture Dynamics. Modeling of the Organizational Culture Dynamics, Quality, access to success, 17(150), 97-104.

Handy, C. (1989), The Age of Unreason, London Business Books.

Hart, S. (2007), Beyond Greening: Strategies for a sustainable world, Harvard 
Business School Press, pp. 109-111.

Holliday, M (2010), Coaching, Mentoring \& Managing: Breakthrough Strategie to Solve Performance Problems and Build Winning Teams, The Career Press, Inc.

Jones, Q. et all (2011), In great company, unlocking the secrets of cultural transformation, A Human Synergistics Publication, pp. 23.

Kaufman, J. (2010), The personal MBA, Penguin, pp. 218-219.

PICBE $\mid 850$

Mckenna, E. and Beech, N. (2002), Human Ressource Management, a concise analysis, Financial Times Prentice Hall, pp. 240-250.

https://www.forbes.com/sites/markmurphy/2015/07/16/leadership-styles-are-oftenwhy-ceos-get-fired/\#7df1e7954988.

https://www.officevibe.com/blog/infographic-employee-feedback.

http://gmj.gallup.com/content/124214/driving-engagement-focusing-strengths.aspx. http://www.businessperform.com/blog/2010/10/05/gallup-employee-feedback358.html.

https://www.weforum.org/agenda/2016/01/the-10-skills-you-need-to-thrive-in-thefourth-industrial-revolution/.

http://www.paecon.net/PAEReview/issue20/Constanza20.htm, iunie 2003/ Constanza R., EcologicalEconomics is Post-Autistic, post-autisticeconomicsreview, issue nr. 20, articolul 2.

http://www.managementmarketing.ro/pdf/articole/302.pdf, Corporateethicalvalues, group creativity, job commitment and performance: the effect of work response on work context. 